\title{
Comparison of analytical and numerical methods in the analysis of the stability of an excavation of the high-speed line in northern Morocco.
}

\author{
Ghizlane Ardouz ${ }^{l, *}$, Khadija Baba ${ }^{l}$, Lahcen Bahi ${ }^{2}$ and Choukri Cherradi ${ }^{l}$ \\ ${ }^{1}$ GCE Laboratory, High School of Technology-Salé, Mohammed V University in Rabat-Morocco. \\ 2 GIE Laboratory, Mohammadia School of Engineers, Mohammed V University in Rabat-Morocco.
}

\begin{abstract}
The deformation and failure mechanisms on slopes and in particular the excavations, are very complex. Slope stability analysis is performed using two types of methods: analytical and numerical, which are compared in this article to evaluate their efficiency. The excavation object of this study is situated on the high-speed line between Kenitra and Tangier, specifically in the rural commune of Hjar Nhal, Tangier-Tetouan-Al Hoceima region. It extends for a 1170 m length, its maximum height is $62 \mathrm{~m}$ at the axis. The soil of the site is characterized by pelitic formations with the existence of numerous water sources at the base of the excavation. Modelling by analytical methods showed that the excavation did not present a stability problem, contrary to numerical modelling. Firstly, the analysis of the results shows that before the failure, the soil is continuous and that its behaviour cannot be analysed by analytical methods, because a fracture surface cannot be established. It is then necessary to consider numerical methods that take into account the entire volume to analyze the movements and their evolution over time. Secondly, hypotheses have been made about the possibility of a poor estimation of the mechanical characteristics of the soils that constitute the excavation. The review of geotechnical investigations has shown that these soils are coarse with discontinuities that favour water infiltration, and are difficult to characterize, which can lead to an overestimation of their mechanical characteristics.
\end{abstract}

\section{Introduction}

Coarse soils are frequently found in nature, especially in mountainous areas. These soils are composed by a combination of elements of different natures and sizes, varying from a fraction of microns (clay particles) to tenths of centimeters (boulders, for example). The construction on this type of soil, their re-use as embankment materials or excavations requires a good knowledge of these materials.

The presence of large elements in these coarse soils is an important issue in terms of their mechanical characterization. In particular, there are still no robust methods for taking these soils into consideration in a rational way in projects, for the calculation and the dimensioning of structures ( deformability parameters, failure criteria, etc...)[1].

The characterization of these soils by conventional geotechnical methods is however very complicated, if not impossible, because of the presence of heterogeneity ( stones, gravels, blocks...) from decimetric to metric size, for at least two reasons [2]:
- Firstly, the use of in situ tests (dynamic penetrometer, static tests, pressiometric tests, etc.) is inappropriate for the very heterogeneous nature of these materials [2].

- Secondly, the maximum size of the elements concerned requires a very large representative soil volume that is much larger for conventional soil testing equipment. When sampling these materials, large diameter particles or blocks ( $>50$ or $100 \mathrm{~mm}$ ) are generally capped to limit the volume of soil samples collected and returned to the laboratory for geotechnical testing. This process usually causes an underestimation of the mechanical characteristics of the material (Holtz, 1961 ; Rathee, 1981; Aboura, 1999) [2].

In this paper, a comparative study between analytical and numerical analysis was established to better understand the mechanism for activating instabilities that occur on railway excavation. The heterogeneous nature of the coarse materials constituting the excavation was the principal initiating factor. The soils found present discontinuities which, on one side, facilitate water infiltration, and on the other side are difficult to be characterized, which can overestimate their mechanical characteristics. 


\section{Presentation of the study area}

\subsection{Geographical context}

The excavation object of this study is located on the high-speed line between Kenitra and Tangier, specifically in the rural commune of Hjar Nhal, in the region of Tanger-Tetouan-Al Hoceima.

It extends for $1170 \mathrm{~m}$ in length, its maximum height is $62 \mathrm{~m}$ at the axis [3].

\subsection{Geological context}

The hill of Hjar Nhal where the excavation is realized represents the northwestern fringe of the Numidian sandstone aquifer. It is a formation that was transported during the Rifan tectonic movements, and which rests on the clay pelites of the Tangier Lower Unit. According to the geological map of Tangier (Figure $1 \& 2$ ), this aquifer is formed in the upper part by an alternation of sandstone and pelites, at the base of this formation more of clay or pelitic levels are present [3].

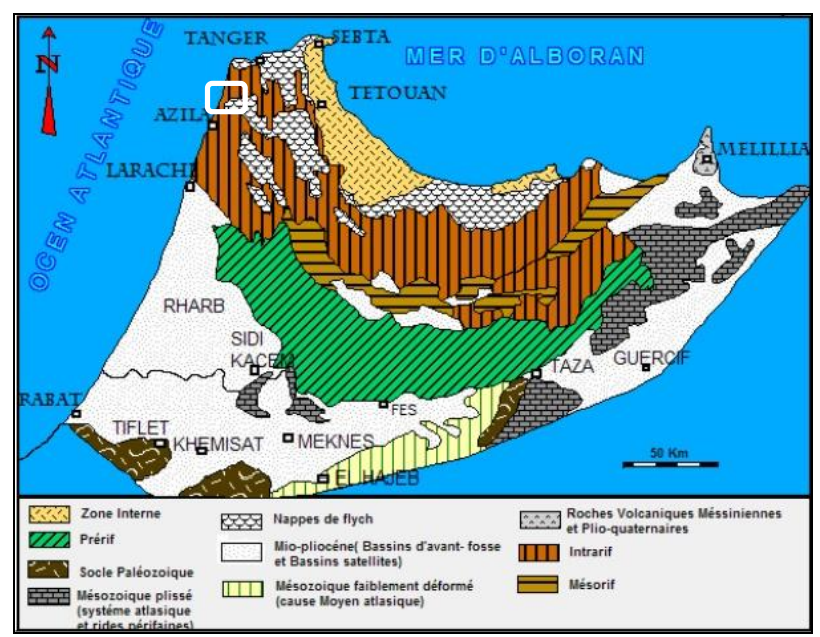

Fig. 1. Carte géologique simplifiée du Rif. (Suter, 1980 : carte géologique du Rif au 1/500000).

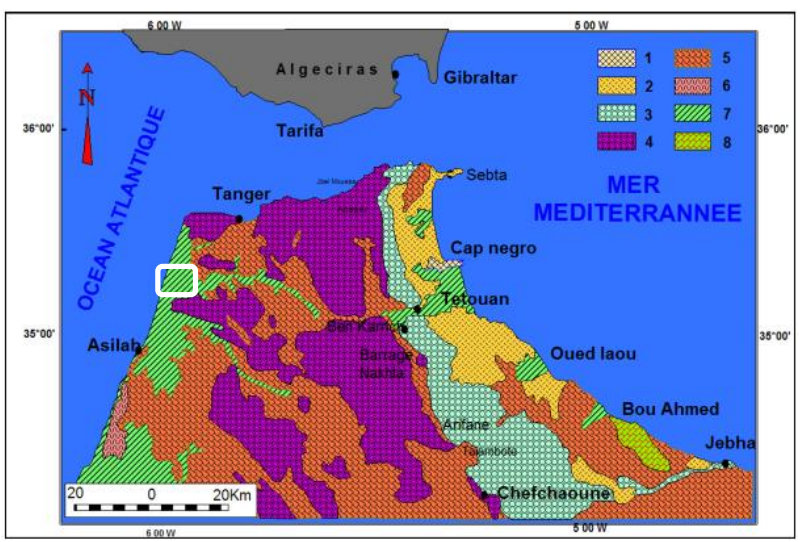

Fig. 2. Principales unités structurales du Rif septentrional. (D'après Suter, 1980 : carte géologique du Rif au 1/500000). 1- Sebtides, 2- Ghomarides, 3- Dorsale calcaire, 4- Nappes de flyschs, 5- Unités intrarifaines, 6- Prérif, 7- Néogène et Quaternaire, 8- Péridotides de Béni Bouchraa.
From a lithological point of view, we therefore distinguish:

- Alternating layers of sandstone (G2) and altered pelites (E5a);

- The pure pelites (E5) in the bottom of excavation;

- The surface is covered with red clays $(\mathrm{E} / \mathrm{C})$.

\subsection{Hydrogeological context}

Piezometric measures could not be realized on superposed aquifers (no selective piezometers). However, it appears that sandstone is relatively porous $(\mathrm{n}=12 \%)$ and therefore potentially aquifers with alternating more clayey levels of pelites probably constituting the wall of these aquifers [3].

This is confirmed by the existence of many sources at the base of the excavation, at the interface between numidian sandstones and the pelites of the Tangier nappe [3].

\section{Geotechnical synthesis}

The geotechnical investigations under the law of the structure have involved numerous in situ and laboratory tests [3].

\subsection{Classification and description of the different formations}

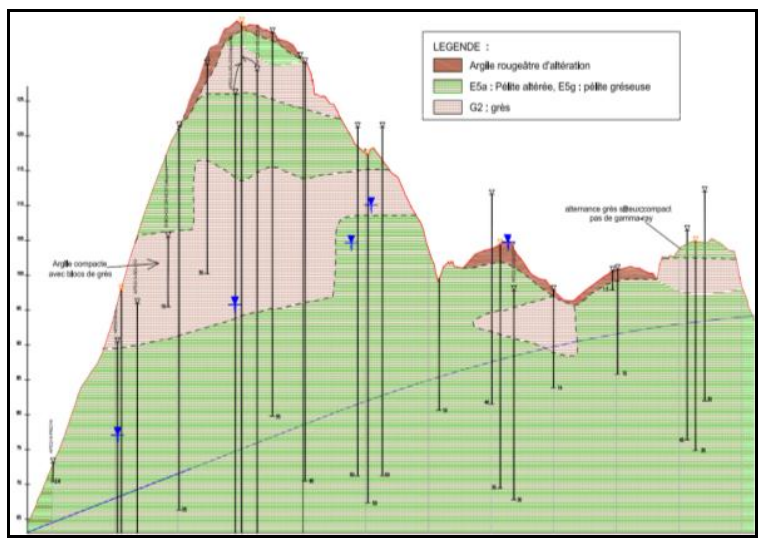

Fig. 3. Geotechnical length profile of the excavation with the implementation of the various surveys.

The following categories of materials are defined:

-E/C: Colluvial cover soils with a predominantly of clay; -E5a : alteration products of pelites, mainly between 0 and $10 \mathrm{~m}$;

-E5: pure, rocky pelites;

-E5g : alternation of pelite and sandstone (sandstone banks representing between 15 and $40 \%$ );

$-\mathrm{E} 5 \mathrm{~g} / \mathrm{G}$ : alternation of pelite and sandstone in approximately equal proportions - G2 : sandstone, with pelitic beds (less than $20 \%$ pelite) ;

-Ga: sandstone alteration [3].

\subsubsection{Formation of surface $E$ / C: screes, colluvions}


These materials, described as bright red clays, are the result of alterations, sometimes colluviated, of the underlying materials (pelites). They are located on the first 2 meters, and are located on the top of the hills [3].

The results of laboratory tests on the samples allocated to this formation show that they are principally clay materials classified as A2 and A3. The water status is generally humid with water contents of $21 \%$ on average.

\subsubsection{Pelitic formations}

In terms of identification, it is very difficult to identify the different pelitic formations. In particularly, the tests realized in sandstone bank pelites were carried out either in sandstone banks - in which case the results are then linked to G2 sandstones - or in pelite banks, whose characteristics are very similar to the altered E5a or healthy E5 pelites. All pelitic materials are materials containing a significant proportion of fines, which are mainly classified as A2 according to the GTR (52\%), with a minority fraction of A3 (35\% of the total). In place, these materials are probably classified as R34 (7\% of the samples) - they are most probably E5 pelites or E5g pelitic beds [3].

The water conditions are essentially "m" (36\%) and "s" (40\%). There does not appear to be any significant difference between the water states of E5a and deeper pelites (E5 and E5g).

The average IPI is 19. As such, we can differentiate between the most altered facies (IPI $=14$ on average) and the healthier ones (IPI $=28$ to 63 ).

The swelling values measured at immersion in a CBR mold are between 1.2 and $2 \%$, which is in the average of the pelitic samples. However, one sample showed a swelling of $20.7 \%$. If this value is not the result of a data input error, it tends to show that there is a significant risk of meeting highly swollen levels within the pelites [3].

\subsubsection{Numidian sandstone G2 and their alteration $\mathrm{Ga}$}

These materials are classified R43 to R41 / R42 (50\% each) for the most indurated levels [3].

\subsection{Triaxial test}

Two triaxial tests were carried out in altered pelites and surface clays. The characteristics adopted for each facies are:

Table 1. Mechanical soil characteristics applied in the calculations [3].

\begin{tabular}{|c|c|c|c|}
\hline Facies & $\begin{array}{c}\text { Cohesion } \\
(\mathrm{kPa})\end{array}$ & $\begin{array}{c}\text { Internal } \\
\text { friction }\left(^{\circ}\right)\end{array}$ & $\begin{array}{c}\text { Density } \\
(\mathrm{kN} / \mathrm{m} 3)\end{array}$ \\
\hline Surface clays & 5 & $25^{\circ}$ & 18.7 \\
\hline $\begin{array}{c}\text { Altered } \\
\text { pelites }\end{array}$ & 28 & $17^{\circ}$ & 19 \\
\hline
\end{tabular}

\begin{tabular}{|l|l|}
\hline Sandstone & Substratum \\
\hline
\end{tabular}

\subsection{In-situ tests}

Seismic profiles have been made in the right of the core drilling. The results show that the different facies (pelites-sandstone) are not distinguishable in terms of seismic velocity. On the other hand, the depth of alteration, which is relatively homogeneous from the surface, is observed:

- Between 5 and $10 \mathrm{~m}$ depth, $\mathrm{V}=300$ to $600 \mathrm{~m} / \mathrm{s}$;

- Between 10 and $30 \mathrm{~m}$ depth, $\mathrm{V}=1000$ to $1500 \mathrm{~m} / \mathrm{s}$;

- Between 30 and $50 \mathrm{~m}$ depth, $\mathrm{V}=2000$ to $2500 \mathrm{~m} / \mathrm{s}$;

- Above 40 to $50 \mathrm{~m}$ depth, $\mathrm{V}>3000 \mathrm{~m} / \mathrm{s}$;

The parameter records also do not distinguish between the two facies, but the altered area is well distinguished about 2 to $5 \mathrm{~m}$ from the surface [3].

\section{Analytical analysis of the stability of the excavation}

The model was as follows:

- Colluvium: thickness $=1 \mathrm{~m}$;

- Altered pelites: thickness $=8 \mathrm{~m}$;

- Sandstone (substratum) at a depth of $9 \mathrm{~m}$;

- No groundwater;

- Slope $=2 \mathrm{~h} / 1 \mathrm{v}$.

For the seismic calculation, the following parameters were used:

- $\mathrm{ah} / \mathrm{g}=0.138$

$-\mathrm{av} / \mathrm{g}=0.069$

Table 2. Stability calculation results (upper part of the excavation).

\begin{tabular}{|c|c|c|}
\hline \multicolumn{3}{|c|}{ Facteurs de sécurité au grand glissement (modélisation } \\
TALREN 4) \\
\hline $\begin{array}{c}\text { Combinaison } \\
\text { fondamentales } \\
\text { (objectif } \mathrm{F} \geq 1.5 \text { ) }\end{array}$ & $\begin{array}{c}\text { Séisme Allégeant } \\
\text { (objectif } \mathrm{F} \geq 0.95)\end{array}$ & $\begin{array}{c}\text { Séisme Pesant } \\
\text { (objectif } \mathrm{F} \geq 0.95)\end{array}$ \\
\hline 2.2 & 1.33 & 1.28 \\
\hline
\end{tabular}
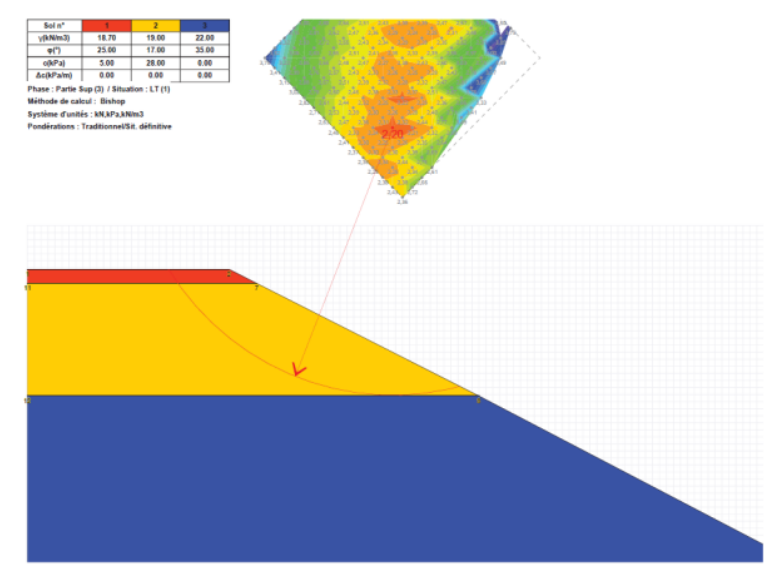

a 


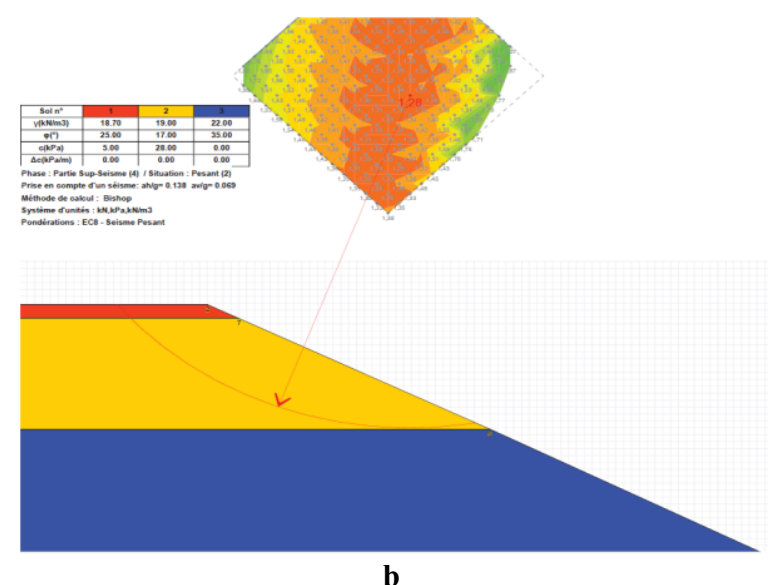

Fig. 4. Stability analysis by Talren: a) long-term traditional situation, b) Eurocode 8 seismic.

Considering the heterogeneity of the excavation, it is not excluded to encounter areas of pure pelite on a significant linear of the excavation. To simulate this possibility, it was considered the alteration of the pelites to a horizontal depth of $3 \mathrm{~m}$ (average value recorded for the alteration in place of the pelites over the entire highspeed line between Kenitra and Tangier), applying the characteristics of the altered pelites E5a. The thickness of the pelites was set at $14 \mathrm{~m}$ (up to the intermediate berm).

The result showed that the alteration of the pelites did not present a stability problem, even without a protective mask. The stability of the slope is $\mathrm{F}=2.40$ (Figure 8.a) (for light and heavy seismic events, the stability factor is 1.55 and 1.50 respectively (Figure $8 . b$ )).
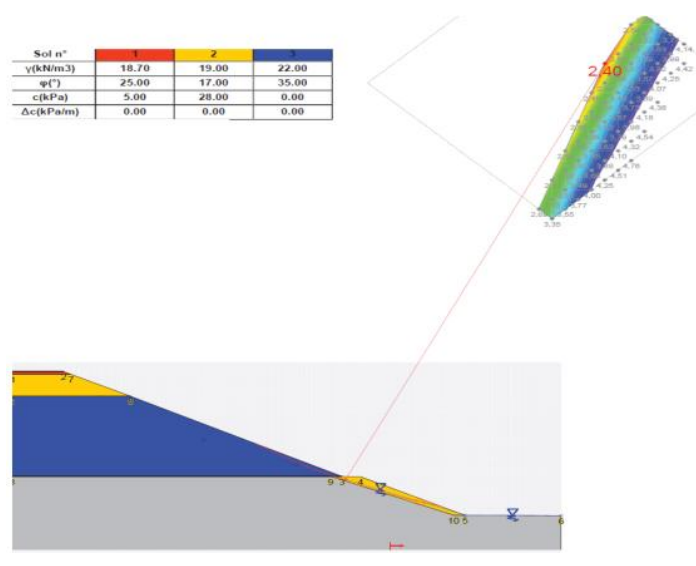

a
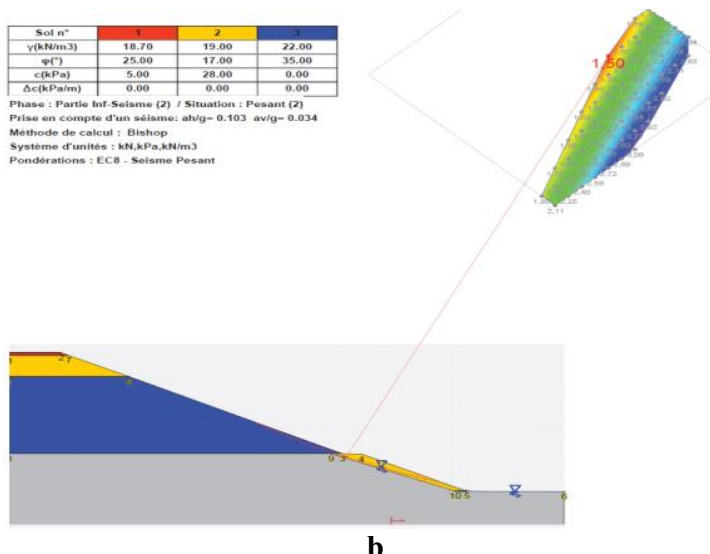

Fig. 5. Stability analysis by Talren: a) long-term traditional situation, b) Eurocode 8 seismic.

\section{Analysis of the events produced}

When the excavation work began, we observed:

- A very significant heterogeneity of the massif, where sandstones represent the minority and the banks are discontinuous or limited to 1 or $2 \mathrm{~m}$ thick, with the only exceptions of a few isolated kidneys or a few banks located in the western slope,

- A significant dissymmetry between the western slope, which is generally more sandy, and where no signs of instability have been observed, and the eastern slope, which is generally pelitic and marked by several landslides,

- A significant fracturation of the massif, clearly apparent on the western slope, or two major failures bring sandstone horizons into contact with pelitic horizons.

The boreholes carried out to install the inclinometers have also revealed the presence of glossy interfacing that can be a contributing factor to the initiation of the sliding mechanism: The excavation was subject to several landslides.

\subsection{Chronology and cinematic of the landslide}

The landslide proceeded in many steps:

- A first sliding (G1) occurred when the slopes of the excavation were on a $2 \mathrm{~h} / 1 \mathrm{v}$ slope. The decision was then made to lay the slopes at $3 \mathrm{~h} / 1 \mathrm{v}$.

- A second sliding (G2) occurred followed quickly by a third (G3) which reactivated while the slope was laid at $3 \mathrm{~h} / 1 \mathrm{v}$.

- A fourth sliding (G4) occurred with the opening of an N240 directional failure at the top of the slope, where the slope was laid at $2.5 \mathrm{~h} / 1 \mathrm{v}$.

These four slides are located in the following figure: 

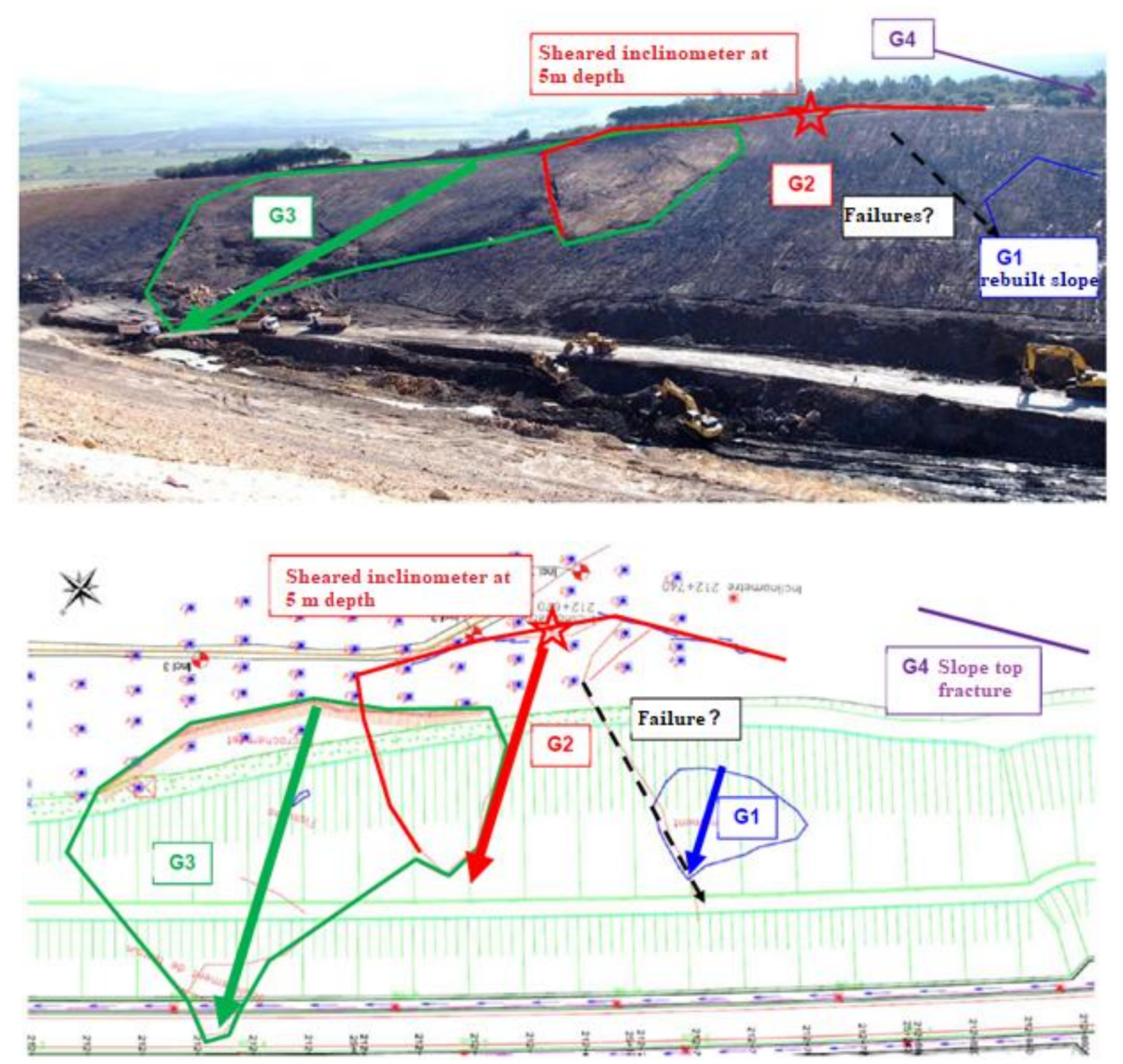

Fig. 6. Situation of the various landslides that occurred on the eastern slope of the excavation.

In terms of cinematic characteristics, the following characteristics can be noted:

- A general direction of the different landslides N350 approximately (arrows), oriented at about $20^{\circ}$ with respect to the slope.

- A top detaching fissure oriented N240 approximately (perpendicular to the direction of sliding), curving N30, parallel to the earth entrance of the slope,

- A cutting ( flaws) with orientation N270 to N330 that can correspond to failures such as those clearly visible on the western slope, and which would cut through the various compartments of the sliding.

- At the G2 sliding level, the inclinometer installed was sheared to a depth of $5 \mathrm{~m}$.

\subsection{Analysis of the facts}

This failure mechanism can be due to multiple factors: - An unfavorable inclination (at about 3h/1v),
- The high sensitivity of pelites to the effect of decompression of the massif: this decompression can cause displacements that motivate the pelites beyond the stress resistance maximum and facilitate the transition into residual characteristics,

- The presence of discontinuities in the massif that favors water infiltration, The presence of sandstone banks which are permeable horizons that can be discontinuous and which facilitate interstitial overpressures. These water flows are probably an important factor in triggering landslides.

\section{Numerical analysis by finite elements of the stability 0 the excavation}

\footnotetext{
*Corresponding author: ghizlane.ardouz@gmail.com
} 
The same problem was analyzed using finite element numerical modelling. Figure 10, below, shows the mesh of the model.

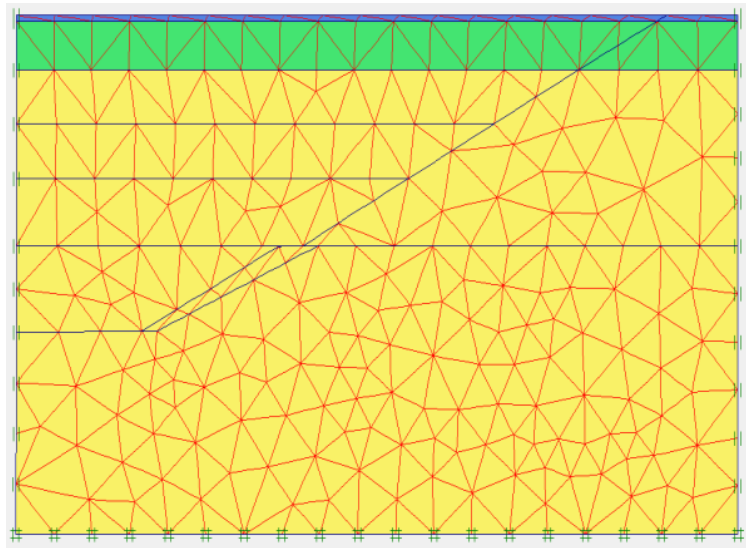

Fig. 7. Finite element model and excavation mesh.

The behaviour of the excavation was modelled using Mohr-Coulomb's elasto-plastic law. A transitional hydromechanical analysis was performed using the Plaxis software and stress and strain variations were traced [4].

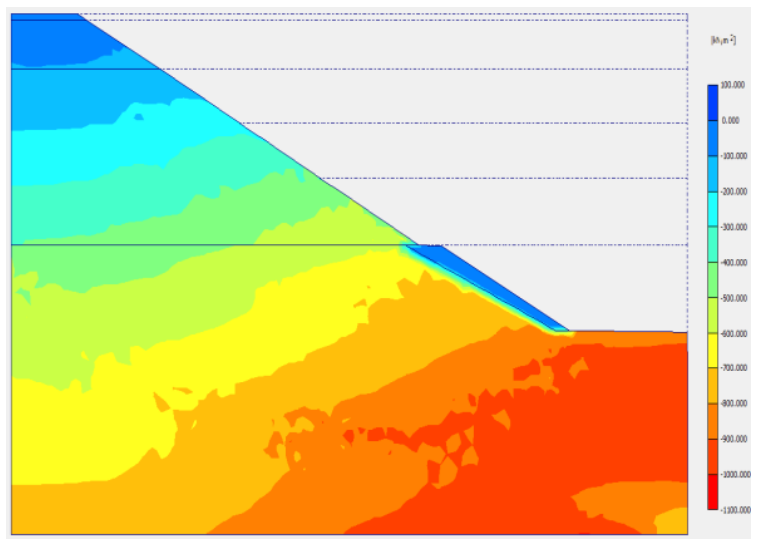

Fig. 8. Shear stresses in the excavation.

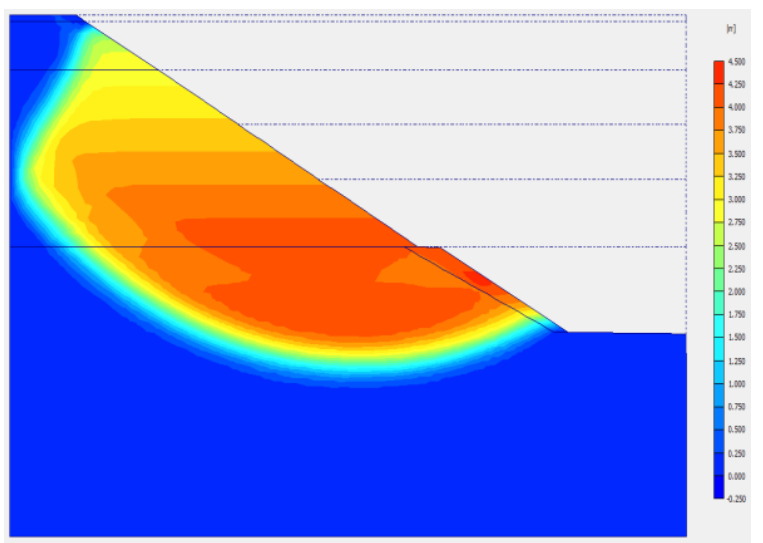

Fig. 9. Horizontal displacements.
In Figure 8, it can be seen that the shear stresses are principally located in the clay layer $(\mathrm{E} / \mathrm{C})$ and the altered pelite layer $(\mathrm{E} 5 \mathrm{~g})$, indicating that a failure mechanism has been developed [4].

\section{Discussions}

The excavation presented in this study was the subject of an analytical analysis which resulted in its stability with a slope of $3 \mathrm{~h} / 1 \mathrm{v}$, but there was an appearance of landslides that could be the result of various factors:

- The presence of sandstone banks, which are permeable horizons that can be discontinuous and favour water infiltration.

- Overestimation of the mechanical characteristics of the soils constituting the excavation, considering their heterogeneity, which makes it difficult to characterize them.

The stability study of this excavation using the finite element method gave results close to the reality of the events that happened. This divergence of results may be due to the fact that the numerical analysis requires, in addition to cohesion and angle of friction, the introduction of other parameters related to the deformability (E) and the permeability of the soil (k).

The soils constituting the body of the excavation are coarse soils characterized by a very spread granulometric distribution. The characterization of these soils in the laboratory or in site is difficult, due to the presence of heterogeneities ( rocks, stones, blocks...) from decimetric to metric dimension, because the test equipments are not adapted to the size of the large elements, and this for at least two reasons:

- Firstly, the use of in situ tests (dynamic penetrometer, static tests, pressiometric tests, etc.) is inappropriate for the very heterogeneous nature of these materials.

- Secondly, the maximum size of the elements concerned requires a very large representative soil volume that is much larger for conventional soil testing equipment. When sampling these materials, large diameter particles or blocks ( $>50$ or $100 \mathrm{~mm}$ ) are generally capped to limit the volume of soil samples collected and returned to the laboratory for geotechnical testing. This process usually causes an underestimation of the mechanical characteristics of the material (Holtz, 1961 ; Rathee, 1981 ; Aboura, 1999). 


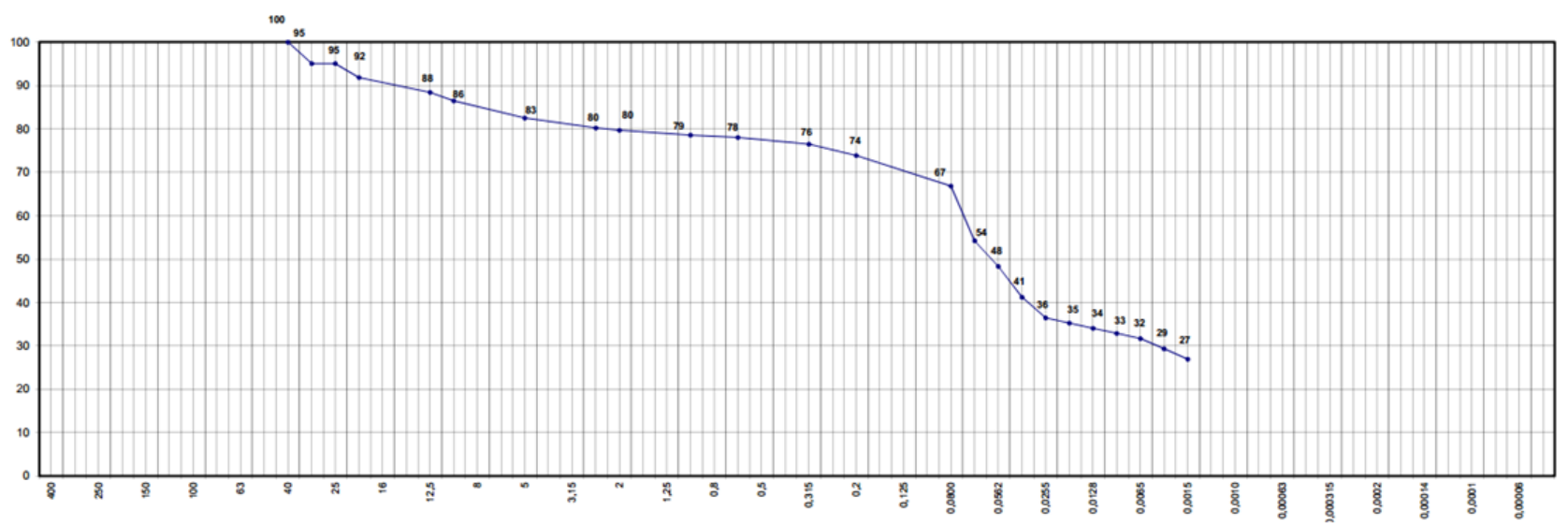

Fig. 10. The granulometric curve of compact surface clays with sandstone blocks (E/C).

\section{Conclusion}

The objective of this article was to analyze the application of analytical and numerical modelling methods on a concrete case of stability of an excavation on the high speed line between Tangier and Kenitra. Analytical methods are generally very conservative, but are easy to use. In this real case, we show the pertinence of numerical modelling when it is well informed (stratigraphic and geomechanical).

It can be concluded from this study that the analysis of the mechanical behaviour of coarse soils is an important issue because they are frequently present in civil engineering works. These materials are characterized by a very spread granulometric distribution.

The heterogeneity of these materials makes them difficult to sample and characterize by traditional geotechnical methods.

These soils have already been the subject of significant work, but there is still no real methodology for taking their mechanical behaviour into account in a rational way. Further research is still needed to better understand them.

\section{References}

1. S. Bassels. Study of the mechanical behaviour of coarse matrix soils. Planet and Universe[physics]. School of Bridges Paris Tech, 2007.

2. E. Rey. Characterization of heterogeneous soils by geophysical methods. Engineering sciences [physics]. Joseph Fourier University - Grenoble I, 2005

3. G. Ardouz and K. Baba. Numerical analysis of instabilities affecting an excavation on the high speed line in northern Morocco. H.Shehata \& al. (Eds). GeoMEast 2019, SUCI, pp. 125-132, 2020.

4. G. Ardouz, K.Baba \& L. Ouadif. Modeling landslides by the finite element method: application to an embankment on a railwayin the Moroccan rif. S. Hemeda and M. Bouassida (Eds). GeoMEast 2018. SUCI, pp 133-141, 2019
5. K. BOUSSAID. Central School of Nantes and University of Nantes (2005)

6. N. Kouakou, O. Cuisinier, F. Masrouri, \& al. JNGGI - Champs-sur-Marne 2018.

7. S. Bassel, J.C. Dupla, R. Frank, \& al. Canadian Geotechnical Journal. 2010.

8. M. Jaboyedoff, T. Oppikofer, M. Henri Derron, et al. Chapter in Geological Society London Special Publications. 2011.

9. N. Prime, F. DUFOUR, F. DARVE. JNGG Grenoble 2010.

10. F. Prunier, F. Darve \& F. Laouafa. 18th French Congress of Mechanics Grenoble. 2007.

11. L. Lyesse, E. John, F. Alessio. Technical bulletin of French-speaking Switzerland. 2010.

12. N. Droniuc. 18th International Conference on Soil Mechanics and Geotechnical Engineering, Paris. 2013.

13. K. Baba, L. Bahi, L. Ouadif and A. Akhssas. Slope Stability Evaluations by Limit Equilibrium and Finite Element Methods Applied to a Railway in the Moroccan Rif. Open Journal of Civil Engineering, Vol. 2 No. 1, 2012, pp. 27-32. 